\title{
Wasting of the hand associated with a cervical rib or band ${ }^{1}$
}

\author{
R. W. GilliatT, PAMELA M. LE QUESNE ${ }^{2}$, VAlENTINE LOGUE, AND \\ A. J. SUMNER ${ }^{3}$
}

From the Institute of Neurology, Queen Square, and the Middlesex Hospital, London

SUMMARY Nine patients are described with unilateral wasting of the hand muscles associated with elongated $\mathrm{C} 7$ transverse processes or with rudimentary cervical ribs. In three patients there was selective wasting of the lateral part of the thenar pad, accompanied by mild weakness of the other hand muscles. In four patients all the hand muscles were wasted, but this was more marked in the lateral part of the thenar pad than elsewhere. In two patients wasting was uniformly distributed throughout the hand. Weakness and wasting in the forearm was only present in four patients and was relatively mild. Sensory loss, when present, affected mainly the inner side of the forearm. Nerve conduction studies revealed no abnormality in the distal part of the median nerve, but some patients had reduced or absent sensory action potentials when the fifth finger was stimulated. In all nine patients a sharp fibrous band was found at operation, which extended from an elongated C7 transverse process or from a rudimentary cervical rib to the region of the scalene tubercle on the first rib. The fibrous band caused angulation of the C8 and T1 roots in five patients, and of the lower trunk of the brachial plexus in three. Pathological changes were frequently visible in affected nerves at the site of angulation. Division of the fibrous band relieved pain and paraesthesiae in eight patients and arrested muscle wasting and weakness in nine patients. There was, however, only slight recovery of power in affected muscles; wasting in the hand appeared to be unchanged after periods of up to eight years.

Earlier accounts of the effects of cervical ribs might seem to have delineated the neurological syndrome so clearly that further description is unnecessary (Howell, 1907, 1913; Bramwell and Dykes, 1921; Sargent, 1921; Wilson, 1913, 1940). For example, the presence of selective thenar wasting in this condition was clearly described by Wilson as early as 1913 . However, the recognition of the carpal tunnel syndrome has caused uncertainty as to whether some of the patients originally thought to have cervical rib syndromes might not have been suffering from unrecognized compression of the median nerve at the wrist.

For this reason we wish to describe nine patients with unilateral wasting of the hand, all of whom had radiological changes suggesting a cervical rib or

\footnotetext{
${ }^{1}$ Based on a paper presented to the Association of British Neurologists, April, 1969.

'Member of the Scientific Staff, M.R.C. Toxicology Unit, Carshalton, Surrey.

'Nuffield Travelling Fellow.
}

band. The clinical pattern was a relatively constant one. Nerve conduction studies not only excluded the carpal tunnel syndrome but, in a proportion of cases, showed evidence of involvement of the brachial plexus or of the lower cervical roots distal to their ganglia. Surgical exploration was carried out in all nine patients and the presence of a local abnormality verified.

\section{NEUROLOGICAL FEATURES}

Some of the clinical features of the nine patients are shown in Table 1.

Previous descriptions of the sex incidence have emphasized that the condition is much commoner in women than in men (for references, see Wilson, 1940). In our own series, all of the nine patients were women. It can be seen in Table 1 that the age of onset varied from 13 to 73 years with a mean of 31 years. However, these figures are based on the patients' own estimates of the duration of their 
TABLE 1

CLINICAL FEATURES

\begin{tabular}{|c|c|c|c|c|c|c|c|c|}
\hline \multirow[b]{2}{*}{ Case } & \multirow[b]{2}{*}{ Patient } & \multirow[b]{2}{*}{ Hospital no. } & \multirow[b]{2}{*}{ Sex } & \multirow[b]{2}{*}{$\begin{array}{c}\text { Hand } \\
\text { involved }\end{array}$} & \multirow[b]{2}{*}{$\begin{array}{c}\text { Age at } \\
\text { onset of } \\
\text { symptoms } \\
(y r)\end{array}$} & \multirow[b]{2}{*}{$\begin{array}{c}\text { Age at } \\
\text { operation } \\
(y r)\end{array}$} & \multicolumn{2}{|c|}{ Duration of symptoms } \\
\hline & & & & & & & $\begin{array}{c}\text { Weakness or } \\
\text { wasting } \\
(y r)\end{array}$ & $\begin{array}{c}\text { Sensory } \\
\text { disturbance } \\
\text { (yr) }\end{array}$ \\
\hline 1 & D.B. & N.H. A 2901 & $\mathbf{F}$ & $\mathbf{L}$ & 13 & 30 & 0.5 & 17 \\
\hline 2 & S.M. & N.H. A39707 & $\mathbf{F}$ & $\mathbf{R}$ & 16 & 20 & 2 & 4 \\
\hline 3 & F.H. & М.H. K82398 & $\mathbf{F}$ & $\mathbf{R}$ & 19 & 33 & 7 & 14 \\
\hline 4 & M.F. & N.H. A20338 & $\mathbf{F}$ & $\mathbf{R}$ & 21 & 24 & 1 & 3 \\
\hline 5 & B.F. & N.H. A16419 & $\mathbf{F}$ & $\mathbf{L}$ & 25 & 25 & 0.33 & 0.25 \\
\hline 6 & F.P. & N.H. 95923 & $\mathbf{F}$ & $\mathbf{R}$ & 29 & 49 & 20 & 20 \\
\hline 7 & I.E. & M.H. J70974 & $\mathbf{F}$ & $\mathbf{R}$ & 40 & 43 & $1 \cdot 5$ & 3 \\
\hline 8 & B.B. & N.H. A 9119 & $\mathbf{F}$ & $\mathbf{R}$ & 45 & 53 & 4 & 8 \\
\hline \multirow[t]{2}{*}{9} & F.D. & N.H. A32722 & $\mathbf{F}$ & $\mathbf{L}$ & 73 & 75 & 2 & 2 \\
\hline & & Mean of group & & & $31 \cdot 2$ & $39 \cdot 1$ & $4 \cdot 3$ & $7 \cdot 9$ \\
\hline
\end{tabular}

symptoms, and they should be regarded as approximate. In most cases several years elapsed between the onset of symptoms and referral to hospital, the mean age at the time of operation being 39 years.

In all nine patients the neurological symptoms and signs were unilateral, although the radiological changes were invariably bilateral ( $v$. infra). It can be seen from Table 1 that it was more common for the neurological syndrome to occur on the right side (six cases) than on the left (three cases). This does not appear to have been related to the patients' handedness as two of the patients with left-sided symptoms and signs were fully right-handed and the third was right-handed for most purposes. All of the six patients with right-sided neurological syndromes were right-handed.

It can be seen from Table 1 that sensory symptoms usually preceded motor involvement. In seven cases the first symptom was pain. This was usually an intermittent ache felt either on the inner side of the arm and forearm, or else a diffuse pain felt throughout the limb. In six cases pain was present without other sensory symptoms at the onset. In one patient paraesthesiae developed at the same time as the pain, and in another the initial complaint was of paraesthesiae without pain. Four other patients noticed paraesthesiae at a later stage.

Paraesthesiae usually took the form of intermittent tingling sensations felt on the inner side of the forearm and in the hand. Both pain and paraesthesiae were sometimes worse after use of the arm. Four patients mentioned specifically that pain occurred at night, but only one (case 8) described paroxysmal nocturnal symptoms of a type usually associated with the carpal tunnel syndrome (Kremer, Gilliatt, Golding, and Wilson, 1953). Numbness of the skin was noticed by four patients; in each case its distribution was on the inner side of the forearm and hand.
Although examination subsequently revealed $\vec{\circ}$ marked muscular wasting in the affected hand, two $\vec{\omega}$ patients stated that weakness had only been present for a relatively short period; one of them had not noticed wasting of the hand until it was pointed out to her by a doctor. It is therefore possible that the figures given in Table 1 underestimate the true duration of motor symptoms in some cases.

The distribution of the muscle wasting revealed by neurological examination was as follows. In three patients wasting was restricted to the lateral part of the thenar pad and affected particularly the abductor pollicis brevis, with sparing of flexof pollicis brevis (cases $1,5,7$ ). An example of mila thenar wasting of this type is shown in Fig. 1, and more severe wasting of similar distribution is show in Fig. 2. On simple inspection this could easily be mistaken for the carpal tunnel syndrome, but in each case there was some weakness of the other small hand muscles, although this was not as marked as in abductor pollicis brevis and opponens pollicis, which were severely weak. In four patients (cases 3 , $6,8,9)$ there was marked atrophy of the lateral part of the thenar pad, but in addition there was definite muscular wasting elsewhere in the hand. An example is shown in Fig. 3. In these patients, weakness of the hand muscles was generalized but was again particularly marked in abductor pollicis brevis and opponens pollicis. In only two patients (cases 2,4 ) was the wasting and weakness uniformly distributed between median and ulnar-supplied hand muscles. $\delta$ In no case was there hypothenar or interosseous weakness or wasting unaccompanied by similar $ᄋ$ changes in the median-supplied thenar muscles.

In comparison with the severity of wasting and weakness in the hand, changes in the forearm were slight. Four patients (cases 2, 4, 6, 9) showed mild o thinning of the flexor mass in the forearm with $N$ weakness of finger flexion and of flexor carpi ulnaris. N 


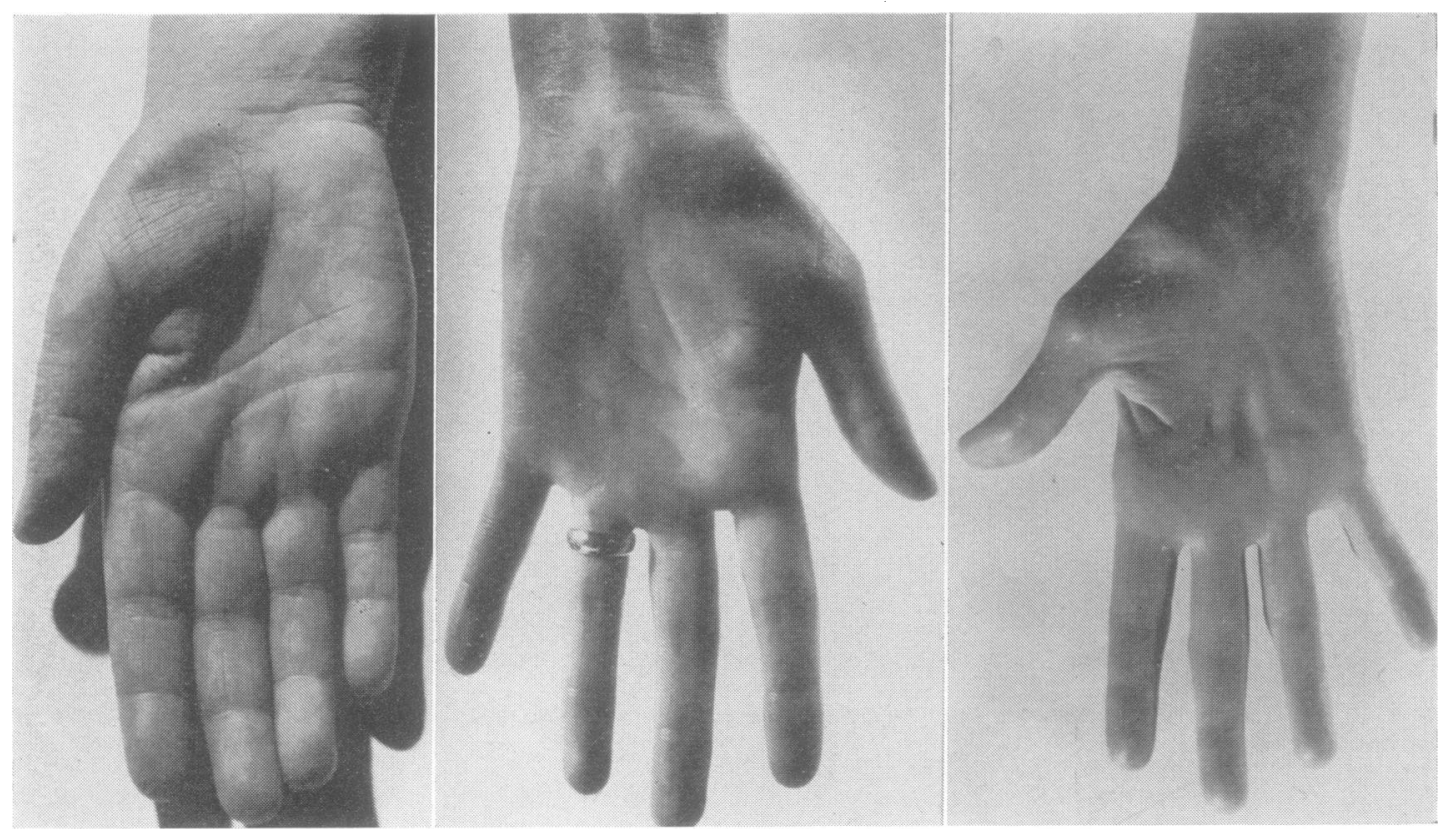

FIG. 1. (Left) Mild thenar wasting in case 7. FIG. 2. (Centre) Marked thenar wasting in case 5. FIG. 3. (Right) Case 3. Wasting throughout the hand but with particularly severe involvement of lateral part of thenar pad.

No wasting of extensor muscles was present but in three of the four patients with flexor weakness (cases $2,6,9)$ slight weakness of finger extension could also be demonstrated; in one of them (case 6) extensor carpi ulnaris was also slightly weak. The remaining muscle groups in the arm were normal, and the biceps, triceps, and supinator jerks were preserved.

In spite of the pronounced sensory symptoms in the patients' histories, the sensory findings on examination were slight. The most constant feature was an area of superficial sensory loss to pinprick and cotton-wool, involving the inner side of the forearm. This was clearly demarcated in five patients (cases 2, 4, 5, 6, 9); in four of them the flare produced by intradermal histamine was reduced or absent. An example is shown in Fig. 4. There were three further patients (cases 1, 3, 7) in whom sensory testing showed only a slight and rather indefinite sensory change on the inner side of the forearm; there was one patient in whom sensation in the forearm was agreed to be normal.

Superficial sensory loss extended from the inner side of the forearm on to the ulnar side of the hand and to the ulnar fingers in two patients (cases 4,6 ). In two others (cases 2, 5) two-point discrimination on the fifth finger was impaired although the appreciation of cotton-wool and pinprick was preserved.
Sensory loss affecting the radial side of the hand or the first and second digits was not seen.

\section{OTHER CLINICAL FEATURES}

Two patients gave a history of a mild Raynaud's phenomenon, but in neither case had this been severe enough to cause them to seek medical advice. On palpation, a bony prominence in the neck was felt in only one patient (case 7). This was felt on the left side although the neurological abnormality was on the right. This patient's radiographs subsequently showed a well-developed cervical rib on the left, which articulated with the first rib, whereas only a rudimentary rib was present on the right.

Auscultation revealed a supraclavicular bruit in only two out of the nine patients. With the affected limb at rest the volume of the radial pulse was normal in all patients, and no colour or temperature change was observed in the affected hand. The changes in the volume of the pulse produced by altering the posture of the affected limb were not considered to be different from those produced in healthy subjects.

\section{ELECTROMYOGRAPHY}

When the affected hand muscles were sampled with 

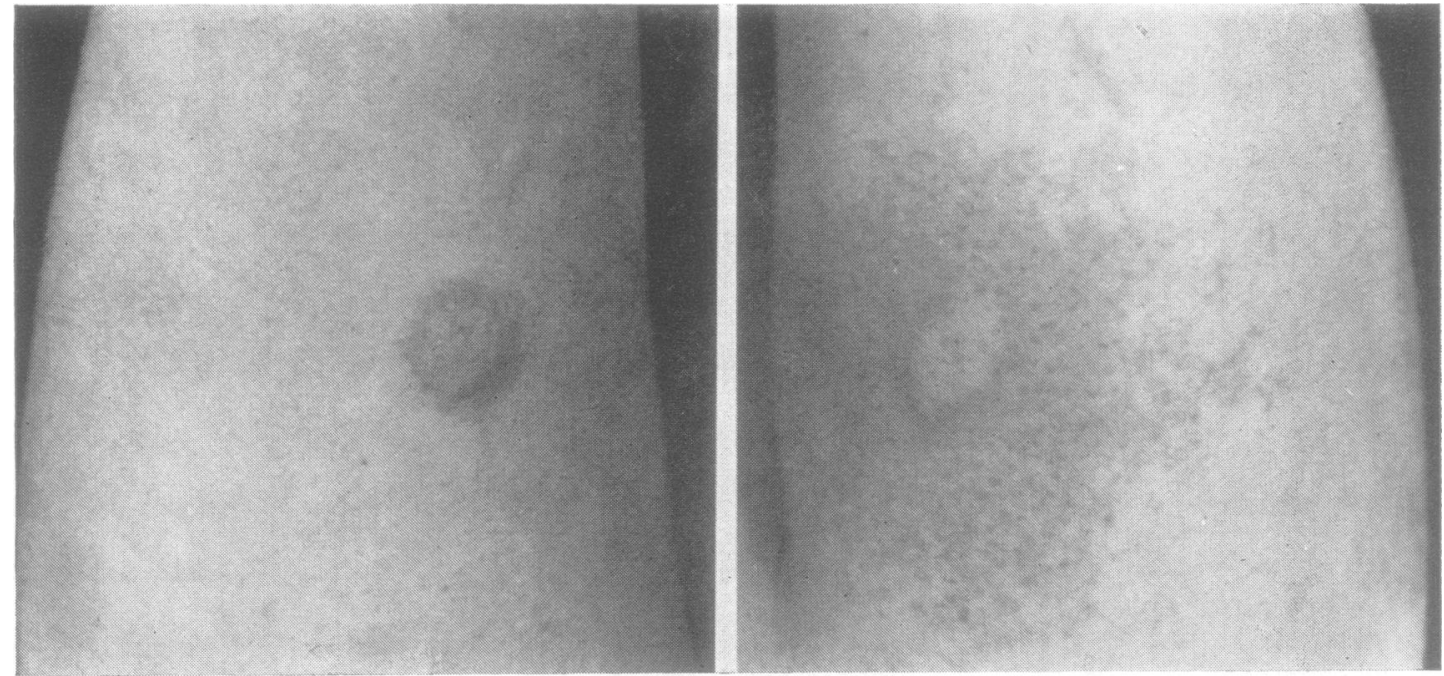

FIG. 4. Case 2. Loss of flare response to intradermal histamine on inner side of affected forearm. Normal response on opposite forearm.

a coaxial needle electrode, spontaneous fibrillation was rarely seen. However, the number of motor units under voluntary control was reduced. In some patients, only one or two motor unit potentials could be found in the thenar pad during attempted voluntary effort. In such cases surviving motor unit potentials were of large amplitude (up to $10 \mathrm{mV}$ ).

Maximal motor conduction velocity was estimated in the median and ulnar nerves of seven patients, the technique being similar to that described by Thomas, Sears, and Gilliatt (1959). Results are shown in Table 2. In the motor fibres to the abductor pollicis brevis muscle, maximal velocity in the forearm was slightly below the lower limit of the normal range in three patients. However, the distal latency was within the normal range in every case. In the ulnar nerve, maximal velocity was estimated in the motor fibres to abductor digiti minimi (two patients) and in the motor fibres to the first dorsal interosseous muscle (five patients); in all cases values for velocity in the forearm and for distal latency fell within the normal range.

To study sensory conduction, the digital fibres of the index and little fingers were stimulated through ring electrodes, ascending action potentials being recorded from the median and ulnar nerves at the wrist, as described by Gilliatt and Sears (1958). From Table 3 it can be seen that there was no reduction in the amplitude of the median nerve action potentials. However, when the little finger was stimulated, there were four patients in whom the ulnar nerve action potential was absent. In a further patient the amplitude of the ulnar nerve action potential was reduced, and in three others the amplitude was in $\mathrm{F}$ the lower part of the normal range. In both the median and the ulnar nerves, the latency of sensorye $\rightarrow$ action potentials was normal; no dispersion of the potentials was seen.

Illustrative tracings from case 5 are shown in Fig. 50 The patient had wasting confined to the thenar paff. (Fig. 2), but in addition there was weakness of the ulnar-supplied intrinsic muscles. There was superficial analgesia and anaesthesia on the inner side of the forearm with loss of the histamine flare. In the hand, appreciation of pinprick and cotton-wool was normal, the only sensory defect being a slightly raised threshold to compass points on the fifth finger. From Fig. 5 it can be seen that electrical stimulation of the digital nerve fibres in the fifth finger gave rise to a small ulnar nerve action potential of normal latency, its amplitude being only $6 \mu \mathrm{V}$. The amplitude of the median nerve action potential evoked by stimulation of the index finger was $40 \mu \mathrm{V}$; corresponding figures for the opposite hand were $34 \mu \mathrm{V}$ for the median and $18 \mu \mathrm{V}$ for the ulnar nerve action potential.

\section{RADIOLOGICAL FEATURES}

Tracings of the radiographs of eight patients are shown in Fig. 6. The side of the neurological syndrome is given after the case number for each tracing. The characteristic finding was an abnormal seventh cervical transverse process which was elongated 
TABLE 2

MAXIMAL CONDUCTION VELOCITY AND DISTAL LATENCY

\begin{tabular}{|c|c|c|c|c|}
\hline Case & Nerve & Muscle & $\begin{array}{c}\text { Forearm } \\
\text { conduction } \\
\text { velocity } \\
(\mathrm{m} / \mathrm{s})\end{array}$ & $\begin{array}{r}\text { Distal } \\
\text { latency } \\
\text { (msec) }\end{array}$ \\
\hline \multirow[t]{2}{*}{$\begin{array}{l}1 \\
2 \\
3 \\
4 \\
5 \\
7 \\
9\end{array}$} & $\begin{array}{l}\text { Median } \\
\text { Median } \\
\text { Median } \\
\text { Median } \\
\text { Median } \\
\text { Median } \\
\text { Median }\end{array}$ & $\begin{array}{l}\text { APB } \\
\text { APB } \\
\text { APB } \\
\text { APB } \\
\text { APB } \\
\text { APB } \\
\text { APB }\end{array}$ & $\begin{array}{l}53 \cdot 0 \\
54 \cdot 0 \\
45 \cdot 5 \\
50 \cdot 0 \\
56 \cdot 5 \\
59 \cdot 0 \\
46.0\end{array}$ & $\begin{array}{l}3 \cdot 9 \\
4 \cdot 0 \\
4 \cdot 0 \\
4 \cdot 0 \\
3 \cdot 8 \\
4 \cdot 2 \\
4 \cdot 0\end{array}$ \\
\hline & & Normal range & $51 \cdot 8-67 \cdot 1 *$ & $2 \cdot 9-5.0 \dagger$ \\
\hline \multirow[t]{2}{*}{$\begin{array}{l}1 \\
2 \\
3 \\
5 \\
6 \\
8 \\
9\end{array}$} & $\begin{array}{l}\text { Ulnar } \\
\text { Ulnar } \\
\text { Ulnar } \\
\text { Ulnar } \\
\text { Ulnar } \\
\text { Ulnar } \\
\text { Ulnar }\end{array}$ & $\begin{array}{c}\text { ADM } \\
1 \text { st DIO } \\
1 \text { st DIO } \\
1 \text { st DIO } \\
1 \text { st DIO } \\
\text { ADM } \\
\text { 1 st DIO }\end{array}$ & $\begin{array}{l}58 \cdot 3 \\
54 \cdot 0 \\
48 \cdot 3 \\
57 \cdot 0 \\
49 \cdot 0 \\
60 \cdot 5 \\
52 \cdot 0\end{array}$ & $\begin{array}{l}2 \cdot 7 \\
3 \cdot 5 \\
4 \cdot 0 \\
4 \cdot 2 \\
3 \cdot 0 \\
2 \cdot 8 \\
4 \cdot 0\end{array}$ \\
\hline & mal range & $\begin{array}{c}\text { ADM } \\
\text { 1st DIO }\end{array}$ & $\begin{array}{l}49 \cdot 0-65 \cdot 6^{*} \\
46 \cdot 2-66 \cdot 2^{*}\end{array}$ & $\begin{array}{l}2 \cdot 0-3 \cdot 7 \ddagger \\
3 \cdot 0-5 \cdot 0 \ddagger\end{array}$ \\
\hline
\end{tabular}

*Thomas et al. (1959).

†Thomas (1960).

†Ebeling et al. (1960).

and tended to curve downwards. The transverse process sometimes narrowed abruptly near the tip to give the appearance shown on the left-hand side in case 9. Sometimes a joint was present at the point of narrowing, separating the transverse process itself from a rudimentary cervical rib (cases 1,7 , and 9). In two patients a relatively large, well-formed bony, rib was present (cases 3 and 7), but it is interesting that in both of them the neurological syndrome was associated with the lesser bony abnormality on the opposite side.

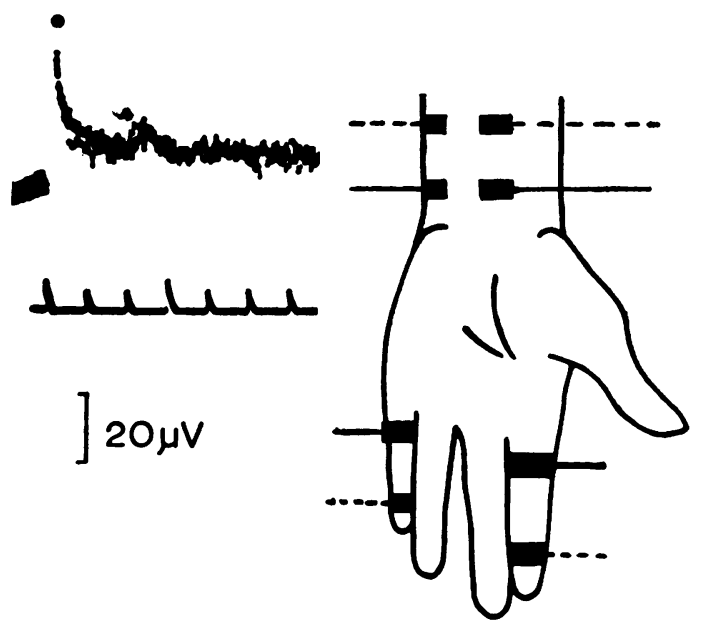

TABLE 3

AMPLITUDE OF SENSORY NERVE ACTION POTENTIALS

\begin{tabular}{ccc}
\hline Case & $\begin{array}{c}\text { Median } \\
(\mu V)\end{array}$ & $\begin{array}{c}\text { Ulnar } \\
(\mu V)\end{array}$ \\
\hline 1 & 48 & 15 \\
2 & 40 & 0 \\
3 & 32 & 8 \\
4 & 50 & 0 \\
5 & 40 & 6 \\
6 & 24 & 0 \\
7 & 27 & 9 \\
8 & 15 & 0 \\
9 & 35 & 10 \\
\hline Normal range* & $9-45$ & $8-28$ \\
\hline
\end{tabular}

*Gilliatt and Sears (1958).

The tip of the abnormal $\mathrm{C} 7$ transverse process or of the rudimentary rib was often pointed, as one might expect if a narrow fibrous band were to arise from it. This abnormality was better shown in oblique views than in the standard anteroposterior projection. An example is shown in Fig. 7.

In case 8, which is omitted from Fig. 6, there were long down-curving transverse processes on both sides without actual ribs, the changes being similar to those shown by case 5 .

In all cases the abnormality affected the seventh cervical vertebra; there were no examples of abnormalities of the first dorsal vertebra and its ribs, as described by Walshe (1951) and by Walshe, Jackson, and Wyburn-Mason (1944).

\section{SURGICAL EXPLORATION}

Seven of the nine patients were explored by one of us (V.L.). In the remaining two patients we are
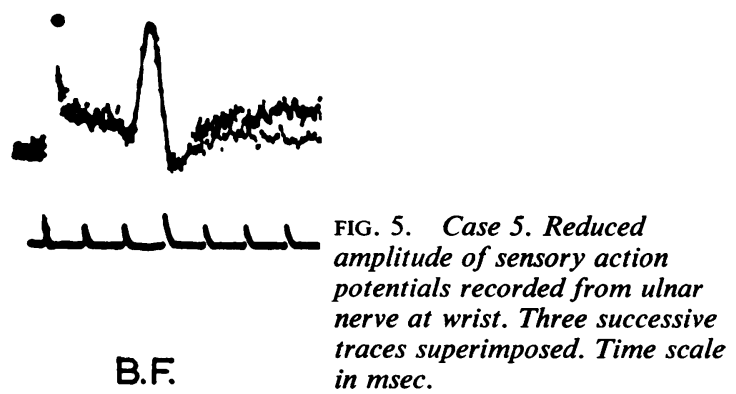

21.2.64. 

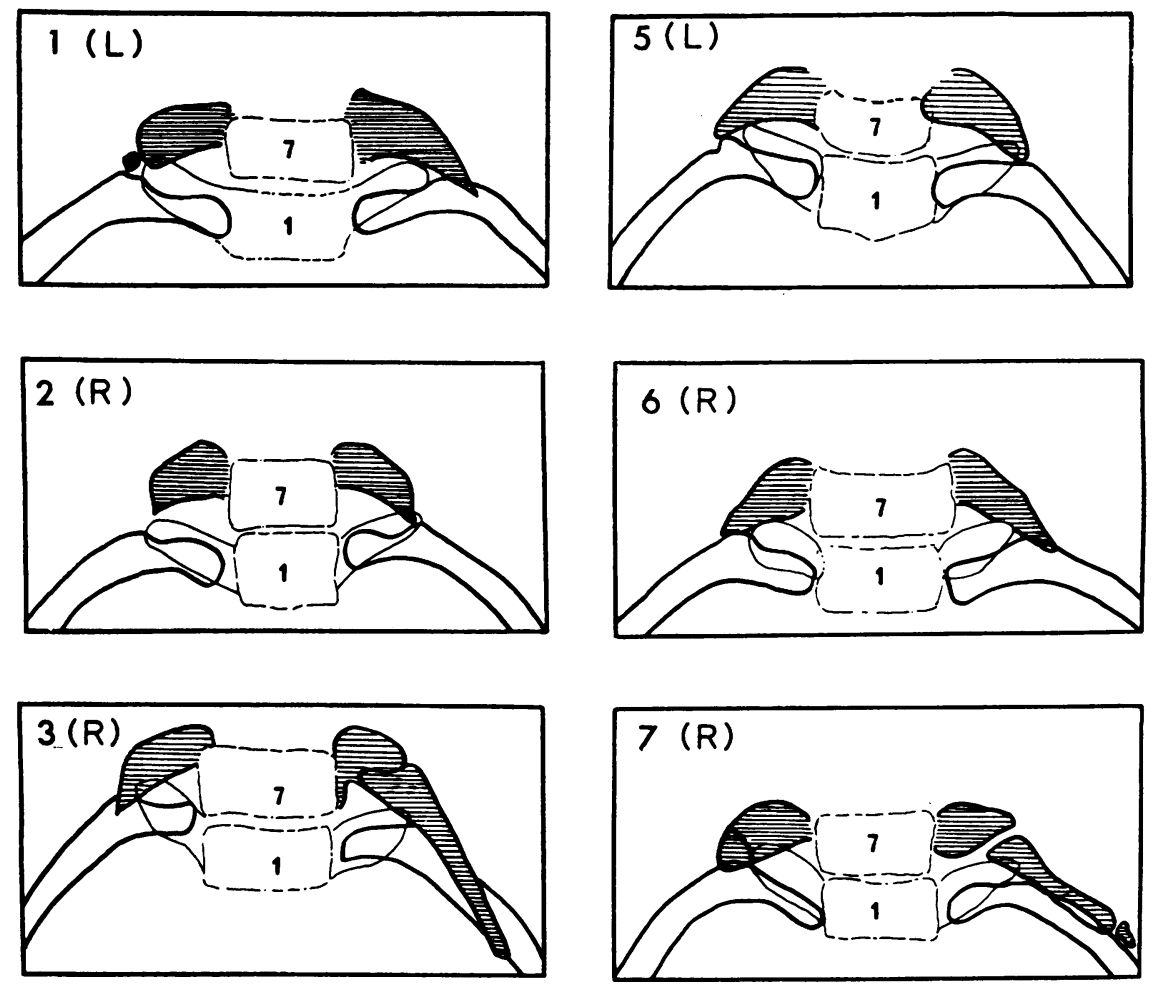

FIG. 6. Tracing of radiographs of thoracic inlet. Side of neurological abnormality is indicated in parentheses after case number (by courtesy of Dr. J.W. D. Bull).
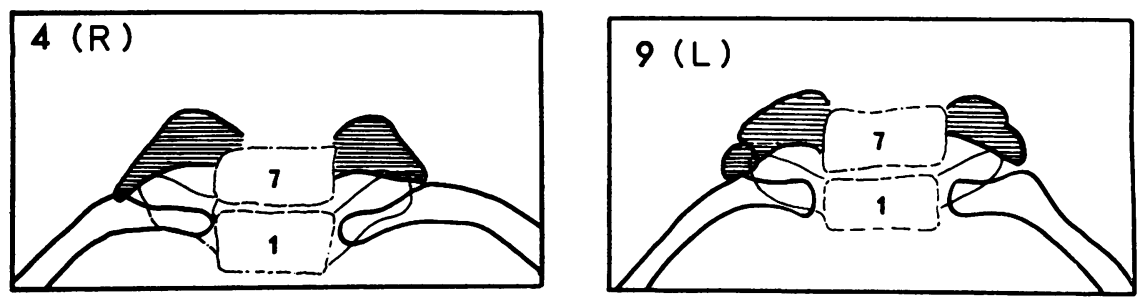

indebted to Mr. Harvey Jackson and Professor G. W. Taylor for permission to quote from their operation notes.

The exploration was through a conventional supraclavicular incisiou In all nine patients the compressing agent was a fibrous band, between 1 and $2 \mathrm{~cm}$ in length, attached to the tip of a rudimentary cervical rib or to the seventh cervical transverse process. On palpation the band was felt as a knife-edge, 1-2 mm across, running downwards and forwards to the region of the scalene tubercle on the first rib, and incorporated into the anterior fibres of the scalenus medius muscle near its inner border. Owing to the different inclination of the brachial plexus from that of the fibrous band, only the anterior $1 \mathrm{~cm}$ of the band came into contact with the nerves. This part of the band produced its mechanical effect by lifting up and stretching forward the lower roots or the lower trunk of the plexus, so that nerve fibres coursing upwards and forwards from the thoracic outlet were angled sharply backwards and downwards over the knife-edge to enter the axilla.

The anatomical formation of the brachial plexus determined which nerve fibres were involved. Out of eight cases in which the observation was made, there were five in which the roots joined to form the three trunks of the plexus lateral to the band, and the involvement was thus at root level. In these cases it was mainly the $\mathrm{T} 1$ root and, to a lesser extent, the 


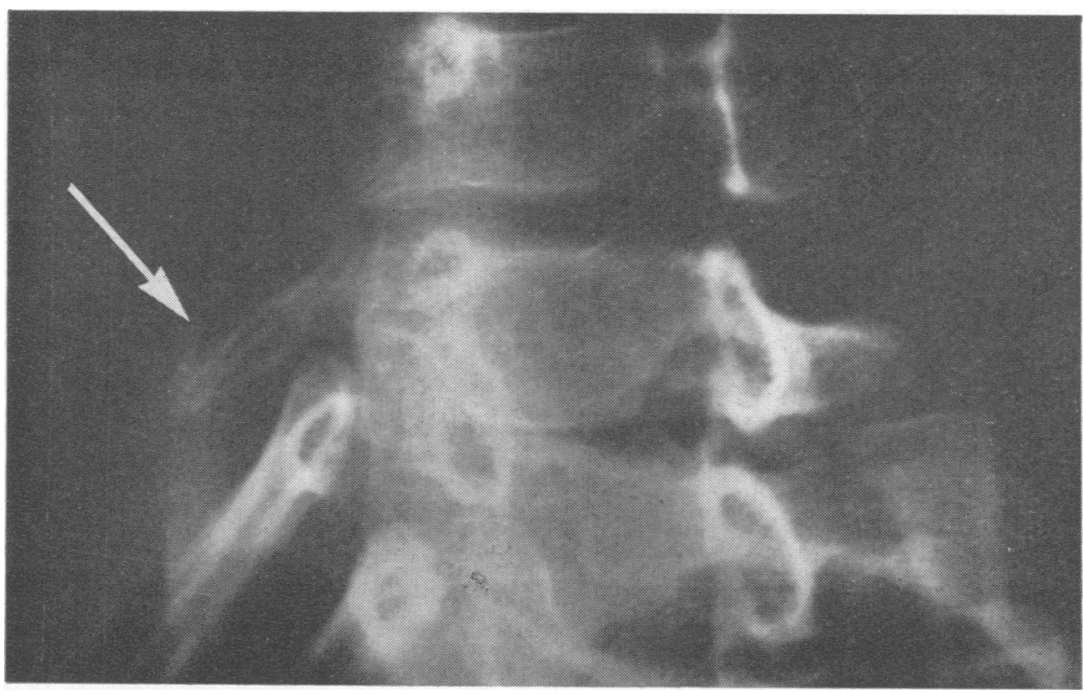

FIG. 7. Case 3. Oblique view of cervical spine to show sharp anterior end of rudimentary rib arising from $C 7$ on right side (by courtesy of Dr. J. W. D. Bull).

C8 root which were in contact with the anterior part of the band. In two patients it was noted that the C7 root was under tension as well, but pathological changes were never seen in this root, whereas flattening or discolouration was frequently seen at the point of angulation in the $\mathrm{T} 1$ root and to a lesser extent in the $\mathrm{C} 8$ root. These roots were sometimes swollen and vascularized either proximal or distal to the indentation caused by the band.

In three patients the roots had joined to form the three trunks of the plexus medial to the band. The trunks were bunched closely together so that it was possible not only for the lower but also for the middle trunk to be in close contact with the band. However, pathological changes of the type described above were seen only in the lower trunk.

Details of the operative findings in individual cases are given in Table 4.

The scalenus anterior muscle was divided partially or completely in seven cases to provide access to the neurovascular bundle behind it. It was not responsible for any active compression and its division did not affect the mechanism of the root stretching. In most of the cases the band was barely in contact with the subclavian artery and therefore incapable of stretching it upwards as the full cervical rib would do. This probably explains the lack of vascular symptoms in these patients.

In all patients the band was excised, and the roots could then be seen to retract back into the gap. In three cases approximately $5 \mathrm{~mm}$ of the bony rib or of the transverse process giving rise to the band was removed as well.
TABLE 4

OPERATIVE FINDINGS

\begin{tabular}{cl}
\hline Case & \multicolumn{1}{c}{ Operative findings } \\
\hline 1 & C8 and T1 roots kinked forwards and upwards by band \\
2 & $\begin{array}{l}\text { C7, C8, and T1 roots stretched over band } \\
\text { C8 and T1 roots flattened with neuroma on T1 lateral to } \\
\text { band } \\
\text { T1 root spread as a broad pinkish-grey film over the band } \\
\text { and adherent to it } \\
\text { Lower trunk of plexus distorted by band, swollen and } \\
\text { oedematous }\end{array}$ \\
\hline 5 & $\begin{array}{l}\text { C8 and T1 roots angulated by band, swollen and more } \\
\text { vascular than usual }\end{array}$ \\
6 & $\begin{array}{l}\text { Fibrous band and bony origin removed. No comment on } \\
\text { state of roots or plexus } \\
\text { Lower trunk of plexus flattened to width of } 12 \text { mm and } \\
\text { angulated over band } \\
\text { Lower and middle trunks of plexus lifted toward and } \\
\text { angulated by band } \\
\text { C8 and T1 roots angulated, particularly T1 root which was } \\
\text { discoloured at site of indentation }\end{array}$ \\
\hline 9
\end{tabular}

\section{RESULTS OF SURGERY}

In most cases there was subjective improvement within the first few days or weeks after operation. Pain and paraesthesiae were relieved in all but our oldest patient (case 9) who was aged 75 at the time of operation. Six patients also reported slightly improved power in the hand. However, this early improvement was slight and was difficult to confirm on formal clinical examination.

As part of a long-term follow-up, five patients (cases $1,5,6,7,8$ ) were seen between five and eight years after operation; this interval should have 
allowed ample time for nerve regeneration if this had been going to occur (cf. Bonney, 1959). In fact, none of the five patients showed significant improvement in the physical signs in the hand itself, although all were pleased by the result of the operation and by the disappearance of pain and paraesthesiae. One of these patients had shown a moderate degree of pre-operative weakness in the forearm with mild wasting of the flexor muscles. In this patient (case 6) muscle wasting was unchanged after eight years. However, power in the forearm muscles was undoubtedly improved, although still reduced compared with the opposite arm.

Electrical studies were repeated at the end of the long-term follow-up, but these did not show a significant change when compared with the pre-operative or immediate post-operative findings. For example, the sensory action potentials recorded from the ulnar nerve, which had been reduced or absent before operation in cases 5,6 , and 7 were still reduced or absent after intervals of five, eight, and six years respectively.

Although the long-term follow-up failed to demonstrate improvement in the hand, it was also clear that there had been no deterioration. All five patients had remained free of pain and paraesthesiae, and the wasting and weakness appeared to have been arrested in each case.

\section{DISCUSSION}

Comparison of our own cases with those described in earlier papers on the neurological effects of cervical ribs reveals interesting similarities and differences. For example, there were eight patients in the series described by Howell (1907), who showed marked weakness and wasting of the hand muscles with milder changes in the forearm muscles, and sensory loss on the inside of the forearm, sometimes spreading to the inner side of the hand. The thenar muscles were often particularly severely affected but in each case there was involvement of ulnar-supplied hand muscles as well. Thus the pattern of neurological involvement in these eight patients closely resembles that described in the present paper.

In addition, however, Howell described five patients with isolated thenar weakness and wasting, the other hand muscles being spared. In two of the patients there was sensory loss affecting the thumb, index, and middle fingers; in the remaining three patients sensation in the hand and forearm was normal. It was Wilson (1913) who subsequently pointed out that the involvement of the thenar muscles was not uniform but that the muscles of the lateral side of the thenar pad were particularly affected. The term 'partial thenar atrophy' was intro- duced by Wilson to indicate that only the abducters pollicis brevis and opponens pollicis were involvef and it was emphasized by Wilson (1940) and subse quently by Walshe (1951) that patients with parti角 thenar atrophy tended to have sensory disturbances on the radial side of the hand; they could thus be distinguished from those with wasting of ulnas supplied hand muscles, whose sensory loss was of the inner side of the hand and forearm.

In the present series we have not seen then $\overrightarrow{\text { f }}$ wasting without some involvement of the ulnaf supplied hand muscles; nor have we seen sensog loss confined to the radial side of the hand. Tht may merely be due to the relatively small number of patients we have seen, but it does raise the poß sibility that some of the patients described in earliêr series were suffering from the carpal tunnel synd drome. Ironically enough, this possibility arises in relation to Wilson's original case of partial thenav atrophy. The patient was under the care of D? Buzzard and was seen by Wilson when he was his house-physician in 1906. A picture of the thenar wasting in the right hand is shown in Fig. 1 of Wilsoff (1913), but few details of the patient's clinical conds tion are given. For this we must turn to the papeplyst Keen (1907) in which we find a case-history sen $\$$ him by Buzzard. Perusal of the in-patient notes at the National Hospital, Queen Square, has confiried that this is the same patient. Keen's paper includies charts of the sensory loss in the right hand whoch involved the thumb, index, and middle fingers, mar ticularly on their palmar surfaces. From the hospitad notes it appears that there was also a suggestion of flattening of the lateral part of the left thenar pad with sensory loss affecting the tips of the thump index, and middle fingers of the left hand, main on their palmar surfaces. This combination of find ings is very suggestive of a bilateral carpal tunne् syndrome. Furthermore, it is clear both from Keen? account and from the hospital notes that operation revealed no abnormality of the brachial plexus in the region of the cervical rib on the right, and the the patient was not helped by removal of the rib.

It may be asked whether the selective involvemen of the median-supplied thenar muscles seen in some of our own patients could have been due to the presence of a carpal tunnel syndrome in addition to the lesion in the neck. This possibility seems to be excluded by the nerve conduction studies. In the carpal tunnel syndrome there is usually a conduction delay between the wrist and the thenar muscles (Simpson, 1956). This is particularly likely to occuir. in patients with thenar wasting or weakness. FoD example, in a series of patients with this diagnosis studied by Goodman and Gilliatt (1961), there wero 27 with thenar wasting or weakness, and normat 
conduction times were present in only two of them. Thus, the normal conduction times from the wrist to the thenar muscles which were recorded in the present series are quite unlike the findings to be expected in patients with the carpal tunnel syndrome. Similar differences exist in relation to sensory conduction. In Goodman and Gilliatt's series, sensory conduction in the median nerve was examined in 33 patients and was abnormal in 29 . In the present series, sensory conduction in the median nerve was normal in every case. There is thus no evidence that even mild median nerve damage at the wrist was contributing to the clinical picture described in the present paper.

It is therefore necessary to explain how a cervical rib or band produces selective wasting of certain muscles in the lateral part of the thenar pad. Even if we do not go as far as Wilson or Walshe in asserting that the other hand muscles may be completely spared, the contrast between the severe changes in abductor pollicis brevis and opponens pollicis, and the mild involvement of other muscles is still a striking one. The patients in our own series who showed this phenomenon most clearly (cases 1,5 , and 7) were in fact those with the shortest history of motor disability, and it may be that partial thenar atrophy tends to occur early in the disease and to be followed later by more generalized wasting of the hand and forearm. In any case, it would seem that the motor fibres supplying the abductor pollicis brevis and opponens pollicis are particularly susceptible to damage at the level of the first rib, although the reason for this is obscure. This problem has recently been reviewed by Sunderland (1968) who concludes that there is no satisfactory anatomical explanation at the present time.

From the practical point of view it is important to recognize that changes may occur in the sensory action potentials recorded from the ulnar nerve at the wrist when the fifth finger is stimulated, since these changes help to distinguish the condition from wasting of the hand due to other causes. For example intraspinal lesions causing wasting of the hand are not associated with any reduction in the amplitude of sensory nerve action potentials (Bonney and Gilliatt, 1958; Fincham and Cape, 1968).

With a lesion at the level of the brachial plexus, an abnormality of sensory conduction in the peripheral part of the ulnar nerve can only occur when there is Wallerian degeneration distal to the lesion; if the cervical rib or band produces only a local conduction block, the sensory action potential at the wrist will be normal. Thus the reduced or absent sensory action potentials recorded from some patients in the present series indicate that afferent fibres had undergone Wallerian degeneration in the nerves concerned. Reduction or loss of the flare produced by intradermal histamine carries the same implication. It should be emphasized that, since nerve conduction tests are concerned with large myelinated fibres, their role is complementary to the use of intradermal histamine which tests the integrity of small-diameter afferent fibres (Lewis, 1927; Celander and Folkow, 1953; Bonney, 1954).

Previous writers have commented that the vascular and neurological syndromes which accompany cervical ribs do not seem to occur in the same patient. Our own experience agrees with this; vascular disturbances were present in only two of our patients and were so mild that they did not cause the patient to seek medical advice. Our results are also in keeping with the comment of Wilson (1940) that: 'On the whole, it is the smaller rib types that affect the plexus, and the larger, the artery, if at all; in the case of bilateral deformities the less substantial one sometimes proves more productive of symptoms than its fellow.' Thus, both our patients who had relatively large cervical ribs on one side and rudimentary ribs on the other, developed the neurological deficit on the side of the lesser bony abnormality (see also Fig. 2 of Bonney, 1965).

This leads to a further question. When the bony abnormality is usually bilateral and often symmetrical, why is the neurological syndrome so often unilateral? Handedness does not seem to be a factor in either our own or previous series (for discussion, see Wilson, 1940). Since rudimentary cervical ribs or long $\mathrm{C} 7$ transverse processes are relatively common in routine cervical spine radiographs and, since a neurological syndrome is relatively rare, the more general question may be asked as to why the bony abnormality should be associated with a neurological deficit in only a small proportion of cases. The critical factor here would seem to be the shape and consistency of the fibrous band attached to the rudimentary rib. It was described as 'knife-like', 'sharp', a 'knife-edge' in notes written at the time of operation on our patients, and this is presumably the determining factor for neurological damage. In this respect our findings are similar to those of Bonney (1965) who operated on 12 patients with wasting of the hand, and found in each case a sharp aponeurotic band passing from the 7th cervical transverse process to the first rib; in most cases there was either an elongated $\mathrm{C} 7$ transverse process or a rudimentary cervical rib but in three instances the cervical spine radiograph had shown no bony abnormality.

What are the indications for operation in this syndrome? From the present series it seems that pain is likely to be relieved by surgery and that weakness and wasting will be arrested but not sub- 
stantially improved. The patients who are likely to benefit from operation are therefore those with troublesome pain and paraesthesiae, and those with a progressive history of weakness and wasting, whereas those with a non-progressive neurological deficit are unlikely to be helped. This is a less optimistic assessment of the effects of surgery than that given by Sargent (1921) who claimed that preoperative muscular wasting was cured in 12 and improved in another 12 patients out of a total of 31 .

Full recovery of power after operation was also described by Brannon (1963) but it is not clear whether wasting of the hand muscles actually disappeared; in some of his cases the follow-up times were in any case too short for regeneration from the level of the first rib to have occurred. However, Bonney's patients were followed for an average of two years and some of them for as long as five years (Bonney, 1965). Improvement in voluntary power and increase in muscle bulk occurred, but Bonney commented that this was most obvious in the forearm muscles and least so in the abductor pollicis brevis.

In our own series slight improvement in power in the immediate post-operative period was noticed by two-thirds of the patients, but little further change occurred in the hand. In one patient with relatively extensive weakness of forearm muscles, the long-term follow-up showed that partial recovery of power in these muscles had occurred.

We are indebted to Dr. John Marshall for permission to include studies on two patients who were under his care (cases 1 and 4). We are also indebted to Professor G. W. Taylor and Mr. Harvey Jackson for permission to describe operative findings in cases 4 and 6 . We wish to thank Dr. J. W. D. Bull, Dr. M. J. McArdle, and Dr. R. G. Willison for helpful discussions.

\section{REFERENCES}

Bonney, G. (1954). The value of axon responses in determining the site of lesion in traction injuries of the brachial plexus. Brain, 77, 588-609.

Bonney, G. (1959). Prognosis in traction lesions of the brachial plexus. J. Bone Jt Surg., 41B, 4-35.

Bonney, G. (1965). The scalenus medius band: a contribution to the study of the thoracic outlet syndrome. J. Bone Jt Surg., 47B, 268-272.

Bonney, G., and Gilliatt, R. W. (1958). Sensory nerve conduction after traction lesion of the brachial plexus Proc. roy. Soc. Med., 51, 365-367.

Bramwell, E., and Dykes, H. B. (1921). Rib pressure and the brachial plexus. Edinb. med. J., 27, 65-88.

Brannon, E. W. (1963). Cervical rib syndrome. An analys of nineteen cases and twenty-four operations. J. Bone Surg., 45A, 977-998.

Celander, O., and Folkow, B. (1953). The nature and dis tribution of afferent fibres provided with the axon refle? arrangement. Acta physiol. scand., 29, 359-370.

Ebeling, P., Gilliatt, R. W., and Thomas, P. K. (1960). clinical and electrical study of ulnar nerve lesions in the hand. J. Neurol. Neurosurg. Psychiat., 23, 1-9.

Fincham, R. W., and Cape, C. A. (1968). Sensory nerve conduction in syringomyelia. Neurology (Minneap.), 18\% 200-201.

Gilliatt, R. W., and Sears, T. A. (1958). Sensory nerve action potentials in patients with peripheral nerve lesions. Neurol. Neurosurg. Psychiat., 21, 109-118.

Goodman, H. V., and Gilliatt, R. W. (1961). The effect of treatment on median nerve conduction in patients with the carpal tunnel syndrome. Ann. phys. Med., 6, 137-155.

Howell, C. M. H. (1907). A consideration of some symptomswhich may be produced by seventh cervical ribs. Lancetw 1, $1702-1707$.

Howell, C. M. H. (1913). The results of operative treatment Proc. roy. Soc. Med. (Clin. Section), 6, 127-132.

Keen, W. W. (1907). The symptomatology, diagnosis, andw surgical treatment of cervical ribs. Amer.J. med. Sci., 133ir 173-218.

Kremer, M., Gilliatt, R. W., Golding, J. S. R., and Wilsan T. G. (1953). Acroparaesthesiae in the carpal-turffe syndrome. Lancet, 2, 590-606.

Lewis, T. (1927). Blood Vessels of the Human Skin and their Responses. Shaw: London.

Sargent, P. (1921). Lesions of the brachial plexus associated with rudimentary ribs. Brain, 44, 95-124.

Simpson, J. A. (1956). Electrical signs in the diagnosis carpal tunnel and related syndromes. J. Neurol. Neuros Psychiat., 19, 275-280.

Sunderland, S. (1968). Nerves and Nerve Injuries. Livingo stone: Edinburgh and London.

Thomas, P. K. (1960). Motor nerve conduction in the carpab tunnel syndrome. Neurology (Minneap.), 10, 1045-1050.

Thomas, P. K., Sears, T. A., and Gilliatt, R. W. (1959). Th\& range of conduction velocity in normal motor nerve fibresn to the small muscles of the hand and foot. J. Neurolo Neurosurg. Psychiat., 22, 175-181.

Walshe, F. M. R. (1951). Nervous and vascular pressure syndromes of the thoracic inlet and cervico-axillary canal. In: Modern Trends in Neurology (pp. 542-566). Edited by Feiling, A. Butterworth: London.

Walshe, F. M. R., Jackson, H., and Wyburn-Mason, R. (1944). On some pressure effects associated with cervical and with rudimentary and 'normal' first ribs and the factors entering into their causation. Brain, 67, 141-177.

Wilson, S. A. K. (1913). Some points in the symptomatologyo of cervical rib, with especial reference to muscular wasting Proc. roy. Soc. Med. (Clin. Section), 6, 133-141.

Wilson, S. A. K. (1940). Neurology, Vol. 2, edited by A. N. Bruce. Edward Arnold: London. 